\title{
Left main occlusion in acute coronary syndrome: percutaneous coronary intervention or coronary artery bypass graft
}

\author{
Edvard Galić*, Krešimir Kordić \\ University Hospital "Sveti Duh", Zagreb, Croatia
}

Coronary artery disease (CAD) is the narrowing or blockage of the coronary arteries, usually caused by atherosclerosis. It is a leading cause of death worldwide, causing approximately 7.2 million deaths worldwide each year. Complete occlusion of LCA is an unusual manifestation of CAD. The reported angiographic incidence is very low, it is found in $0.03 \%$ to $0.8 \%$ of patients in different studies. Occlusion of this vessel compromises flow to at least $75 \%$ of the left ventricle, unless it is protected by collateral flow or a patent bypass graft. Left main coronary artery disease rarely occurs as an isolated lesion; over $70 \%$ to $80 \%$ of patients also have multivessel coronary artery disease. Most patients with this condition complain of recurrent typical chest pain and have a history of myocardial infarction. They may also present with symptoms of heart failure. The diagnosis is usually made by angiography, which reveals a right dominant system. Right coronary artery provides collateral circulation to the left system, but up to two thirds of patients have a marked obstruction of the RCA.

Our report describes two patients with ST-elevation myocardial infarction, who developed cardiogenic shock. In both cases, coronary angiography was performed immediately, and showed total occlusion of LCA and a right dominant system. The first patient was referred to primary PCI LMCA, and the second patient was referred to intraaortic balloon pump placement and multiple CABG. Six months later, both patients remain stable. Uncertainty surrounds the optimal revascularization strategy for patients with ST-elevation myocardial infarction LMCA occlusion and treatment guidelines in this setting are vague. PCl of the LMCA should be considered as a viable alternative to $C A B G$ for selected patients with myocardial infarction, including those with LCA occlusion and less than TIMI flow grade 3, cardiogenic shock, persistent ventricular arrhythmias, and significant comorbidities.

KEYWORDS: acute coronary syndrome, percutaneous coronary intervention, coronary artery bypass graft.

Received: $3^{\text {rd }}$ Mar 2013

*Address for correspondence: Klinička bolnica "Sveti Duh", Sveti Duh 64, HR-10000 Zagreb, Croatia.

Phone: +385-1-3712-111

E-mail: edvard.galic@ zg.t-com.hr 